\title{
Research on the operational risk evaluation model of the electricity selling company under the reform of transmission and distribution price
}

\author{
Weihua Weng ${ }^{1, \text { a }}$, Yan Zhao ${ }^{1, \mathrm{~b}}$, Chunyi Chen ${ }^{1, \mathrm{c}}$, Yaru Meng ${ }^{2, \mathrm{~d}}$, Mi Liu ${ }^{2, \mathrm{e},}$, \\ Dunnan Liu $^{2, f}$ \\ 1Electric power trading center in State Grid Shanghai Power Company, Shanghai 200122, China; \\ 2Department of economics and management in North China Electric Power University, Beijing 102206, \\ China; \\ a wengweihua@sh.sgcc.com.cn, b zhaoyan@sh.sgcc.com.cn, c chenchy@sh.sgcc.com.cn \\ d 451894647@qq.com, e 18701062380@163.com, f liudunnan@163.com
}

Keywords-electricity selling company; operational risk; matter-element extension

\begin{abstract}
With the gradual liberalization of the marketing electricity side in China, the newly established electricity selling companies, in the operation process, will face operational risks from multiple aspects. First, in this paper, the index system of operational risk evaluation for electricity selling companies is established, and 4 first grade indexes and 12 secondary indexes are determined. Then, the matter-element extension model which can fully consider the factors of material and quantity of things to be evaluated is taken as the evaluation model. Finally, an electric company is selected as an example to analyze its operational risk degree.
\end{abstract}

\section{INTRODUCTION}

With the development of a new round of electricity power reform, electricity selling subject has gradually come into the marketing electricity side, whose income mode and service function are similar to those power grid enterprises that make profit margins. Therefore, the relevant research on the operation risk of power grid enterprises before the new power reform can be used for reference to the operation risk management of the electricity selling companies under the reform of transmission and distribution price.

Chengkai Cai analyzed the operation risk of power grid enterprises from two aspects: the risk of purchasing electricity and the risk of selling electricity, in which the description of electricity price risk was mainly carried out in the aspect of selling electricity risk ${ }^{[1]}$. Considering the research on grid operation risk in electricity price, Ming Zhou studied the uncertainty generated by power purchase allocation decisions, and the cost function of purchasing electricity is constructed by analyzing the different performance of spot market, futures market and day-ahead market ${ }^{[2]}$. VazquezC considered that the electricity selling companies need to combine their own situation, and make a depth analysis of the influence of multiple selling price mode combination on electricity selling companies ${ }^{[3]}$. CelebiE, ValeryA mainly introduced different forms of electricity pricing, and analyzed the response of different users to TOU power price ${ }^{[4-5]}$.

\section{CONSTRUCTION OF OPERATION RISK EVALUATION INDEX SYSTEM FOR ELECTRICITY SELLING COMPANIES}

The enterprises that establish the electricity selling companies may come from a number of different 
industries. But, in China, considering the background that the sale side is gradually liberalized and the market mechanism is not yet perfect, even if the industry is different, the newly founded electricity selling company will face the common risk from many aspects in the process of operation. This paper, considering four aspects risk: policy risk, market risk, internal risk and security risk, constructs a set of operation risk evaluation index system for electricity selling companies. Specific as shown in table 1.

TABLE I. OPERATION RISK EVALUATION INDEX SYSTEM OF ELECTRICITY SELLING COMPANY

\begin{tabular}{|c|c|c|}
\hline \multirow{13}{*}{$\begin{array}{l}\text { operation risk } \\
\text { evaluation } \\
\text { index system of } \\
\text { electricity } \\
\text { selling company }\end{array}$} & \multicolumn{2}{|c|}{$\begin{array}{l}\text { operation risk evaluation index system of electricity selling } \\
\text { company }\end{array}$} \\
\hline & first grade index & secondary index \\
\hline & \multirow{2}{*}{ policy risk } & Market entry and exit mechanism \\
\hline & & Policy support \\
\hline & \multirow{4}{*}{ market risk } & Power purchase risk \\
\hline & & Risk of selling electricity \\
\hline & & Market competition risk \\
\hline & & Market trading mechanism \\
\hline & \multirow{3}{*}{ internal risk } & Asset risk \\
\hline & & Power business experience \\
\hline & & Power related technology \\
\hline & \multirow{2}{*}{ security risk } & Natural disaster \\
\hline & & System operation safety \\
\hline
\end{tabular}

(1) policy risk

The reform is guided by the policy. Although the state has been issued a number of documents and notices for the sale of electricity side release, but most are just guidance direction. There is no specific implementation plan to match and no market access system to get into, and government supervision and management have no experience to seek. Although some electricity selling companies have been established, most of them are only "empty shells", which have not been recognized by the government.

(2) market risk

For the electricity selling companies, the market risk is the main risk, which includes the risk of purchasing electricity, the risk of selling electricity, the risk of market competition and the risk of market trading mechanism. The risk of purchasing electricity includes electricity price volatility. The risk of selling electricity includes the user is unable to pay the electricity fee because of the bad management and the serious loss. The risk of market competition includes the relatively backward technology, imperfect operation management system, lack of funds and the low quality of personnel. The risk of market trading mechanism includes the risk of price fluctuation and the risks of different settlement methods caused by a variety of power purchase trading methods, the lack of value-added services and the lack of new services to attract users.

(3) internal risk

In addition to power grid enterprises, the newly established electricity selling companies did not involve related power business on sale side. With different industries coming into sale side and establishing electricity sales company, the company will face much more risk because of internal factors, such as financial risk, power business technology risk. Financial risk includes lack of funds, investment scale mismatch and inappropriate timing of investment. Power business technology risk includes the lack of power sale technology system.

(4) security risk

Generally speaking, the safety risk of electricity selling companies is more accidental. Its source can be analyzed from two aspects: external and internal aspects. External aspects refer to the natural risk of external nonresistance, such as earthquake, typhoon. Internal aspects refer to the internal security 
operation risk, such as imperfect technical support system and lack of experience in selling electricity.

\section{ANALYSIS OF OPERATION RISK EVALUATION MODEL OF ELECTRICITY SELLING COMPANY}

(1) Determine the classical domain and controlled domain. Suppose that the evaluation grade of the object to be evaluated is divided into $m$, and the evaluation index is $n$. The set of value range $v_{i j}=\left[a_{i j}, b_{i j}\right]$ of standard object $P_{i}$, its $n$ eigenvalues $C_{j}$ and its standard value constitute matter element matrix (classical matter element matrix). The matrix is noted as $R_{i}$ :

$$
R_{i}=\left(P_{i}, C_{j}, V_{i j}\right)=\left[\begin{array}{ccc}
p_{i} & c_{1} & v_{i 1} \\
& c_{2} & v_{i 2} \\
& \vdots & \vdots \\
& c_{n} & v_{i n}
\end{array}\right]=\left[\begin{array}{ccl}
p_{i} & c_{1} & \left\langle a_{i 1}, b_{i 1}\right\rangle \\
& c_{2} & \left\langle a_{i 2}, b_{i 2}\right\rangle \\
\vdots & \vdots \\
& c_{n} & \left\langle a_{i n}, b_{i n}\right\rangle
\end{array}\right] \quad i=1,2, \cdots, m
$$

The so-called domain matter element matrix is composed of the classical material elements, things which can be transformed into the classical matter elements, and the value range expanded by the corresponding characteristics of things. The matrix is noted as $R_{p}$ :

$$
R_{p}=\left(P, C_{j}, V_{i j}\right)=\left[\begin{array}{ccc}
p & c_{1} & v_{p 1} \\
& c_{2} & v_{p 2} \\
\vdots & \vdots \\
c_{n} & v_{p n}
\end{array}\right]=\left[\begin{array}{ccc}
p & c_{1} & \left\langle a_{p 1}, b_{p 1}\right\rangle \\
c_{2} & \left\langle a_{p 2}, b_{p 2}\right\rangle \\
\vdots & \vdots \\
& c_{n} & \left\langle a_{p n}, b_{p n}\right\rangle
\end{array}\right]
$$

Among them, $p$ denotes all evaluation grades, and the value range of evaluation index relative to all evaluation grades is expressed by $v_{p 1}, v_{p 2}, \cdots, v_{p n}$. For example, $v_{p j}=\left[a_{p j}, b_{p j}\right]$ represents the value range $R_{p}$ about the evaluation level of the evaluation index $c_{j}$, which is controlled field. And $a_{p j}=\min _{1 \leq i \leq m} a_{i j}, \quad b_{p j}=\min _{1 \leq i \leq m} b_{i j}, \quad j=1,2, \cdots, n$.

(2) Establish matter element matrix to be evaluated. According to the data corresponding to the matter element index to be evaluated, the correlation matrix of the matter-element is set up. The matrix is noted as $R_{0}$ :

$$
R_{0}=\left(P_{0}, C_{j}, V_{j}\right)=\left[\begin{array}{ccc}
p_{0} & c_{1} & v_{1} \\
& c_{2} & v_{2} \\
\vdots & \vdots \\
& c_{n} & v_{n}
\end{array}\right]
$$

(3) Determine correlation function. The extension set is expressed by algebraic expression in association function. It aims at quantitative analysis of the contradiction of mutual exclusion. The whole range of the correlation function is all real numbers $(-\infty,+\infty)$. It can be used to describe the membership degree $i$ of all the features of the object on each grade. 


$$
K_{i}\left(v_{j}\right)=\left\{\begin{array}{l}
-\frac{\rho\left(v_{j}, v_{i j}\right)}{\left|v_{i j}\right|}, v_{j} \in v_{i j} \\
\frac{\rho\left(v_{j}, v_{i j}\right)}{\rho\left(v_{j}, v_{p j}\right)-\rho\left(v_{j}, v_{i j}\right)}, v_{j} \notin v_{i j} \text { 且 } \rho\left(v_{j}, v_{i j}\right) \neq 0 \\
-\rho\left(v_{j}, v_{i j}\right)-1, v_{j} \notin v_{i j} \text { 且 } \rho\left(v_{j}, v_{i j}\right)=0
\end{array}\right.
$$

Among them:

$$
\begin{gathered}
\left|v_{i j}\right|=\left|b_{i j}-a_{i j}\right| \rho\left(v_{j}, v_{i j}\right)=\left|v_{j}-\frac{1}{2}\left(a_{i j}+b_{i j}\right)\right|-\frac{1}{2}\left(b_{i j}-a_{i j}\right),(i=1,2, \cdots, m ; j=1,2, \cdots, n) \\
\rho\left(v_{j}, v_{p j}\right)=\left|v_{j}-\frac{1}{2}\left(a_{p j}+b_{p j}\right)\right|-\frac{1}{2}\left(b_{p j}-a_{p j}\right), \quad(j=1,2, \cdots, n),
\end{gathered}
$$

$K_{i}\left(v_{j}\right)$ expresses the correlation degree between the first $j$ index and the grade $i . \rho$ is the distance function, which represents the distance from the eigenvalue to the finite interval. $\rho\left(v_{j}, v_{i j}\right)$ represents the distance between the first $j$ index value and the first $i$ classical domain. $\rho\left(v_{j}, v_{i j}\right)$ represents the distance between the first $j$ index value and the controlled field. is:

(4) Determine evaluation grade. The comprehensive correlation degree of the objects to be evaluated

$$
K_{i}\left(P_{0}\right)=\sum^{n} w_{j} K_{j}\left(v_{j}\right), \quad i=1,2, \cdots, m
$$

In the formula, the degree of the object to be evaluated $\left(P_{0}\right)$ is expressed as $K_{i}\left(P_{0}\right)$, and the weight of each evaluation index is expressed as $w_{j}$.According to the principle of maximum membership degree:

$$
K_{i *}\left(P_{0}\right)=\max K_{i}\left(P_{0}\right), \quad i=1,2, \cdots, m
$$

So, the object to be evaluated belongs to the grade $i^{*}$, which belongs to the first $i^{*}$ evaluation level.

\section{CASE ANALYSIS}

We invite 5 experts in power market. According to the actual situation of electricity selling companies, the 3 level two indexes of internal risk are contrasted and judgment matrix is constructed. And AHP method is used to determine weights. Each expert determines the weight of the indexes of asset risk, power business experience and power related technology. The results are shown in table 3.

TABLE II. SUMMARY OF INTERNAL RISK WEIGHTS

\begin{tabular}{|l|l|l|l|l|l|}
\hline & Expert 1 & Expert 2 & Expert 3 & Expert 4 & Expert 5 \\
\hline Asset risk & 0.1365 & 0.1007 & 0.2098 & 0.1220 & 0.0914 \\
\hline $\begin{array}{l}\text { Power business } \\
\text { experience }\end{array}$ & 0.2385 & 0.2255 & 0.2402 & 0.2297 & 0.2176 \\
\hline $\begin{array}{l}\text { Power related } \\
\text { technology }\end{array}$ & 0.6250 & 0.6738 & 0.5499 & 0.6483 & 0.6910 \\
\hline
\end{tabular}

According to the AHP-entropy weight combination method, the final weight of each index can be calculated: 
TABLE III. INDEX WEIGHT OF OPERATION RISK EVALUATION FOR ELECTRICITY SELLING COMPANIES

\begin{tabular}{|c|c|c|c|c|}
\hline Total target layer & $\begin{array}{l}\text { First grade } \\
\text { index }\end{array}$ & weight & secondary index & weight \\
\hline \multirow{12}{*}{$\begin{array}{c}\text { Operation risk } \\
\text { evaluation of } \\
\text { electricity selling } \\
\text { company A }\end{array}$} & \multirow[t]{2}{*}{ policy risk B1 } & \multirow[t]{2}{*}{0.213} & $\begin{array}{l}\text { Market entry and exit } \\
\text { mechanism }\end{array}$ & 0.576 \\
\hline & & & Policy support & 0.424 \\
\hline & \multirow{5}{*}{ market risk B2 } & \multirow{5}{*}{0.432} & Power purchase risk & 0.273 \\
\hline & & & $\begin{array}{l}\text { Risk of selling } \\
\text { electricity }\end{array}$ & 0.380 \\
\hline & & & $\begin{array}{l}\text { Market competition } \\
\text { risk }\end{array}$ & 0.167 \\
\hline & & & $\begin{array}{ll}\text { Market } & \text { trading } \\
\text { mechanism } & \\
\end{array}$ & 0.107 \\
\hline & & & Value added service & 0.073 \\
\hline & \multirow{3}{*}{ internal risk B3 } & \multirow{3}{*}{0.237} & Asset risk & 0.127 \\
\hline & & & $\begin{array}{l}\text { Power } \\
\text { experience }\end{array}$ & 0.232 \\
\hline & & & $\begin{array}{ll}\text { Power } & \text { related } \\
\text { technology } & \end{array}$ & 0.641 \\
\hline & \multirow{2}{*}{ security risk B4 } & \multirow{2}{*}{0.118} & Natural disaster & 0.367 \\
\hline & & & System operation safety & 0.633 \\
\hline
\end{tabular}

According to the operating risk evaluation system of electricity selling company, the classical domains of each evaluation level $p_{1}, p_{2}, p_{3}, p_{4}, p_{5}$ represents extremely high risk, high risk, general risk, low risk and extremely low risk. We get the sample of electricity selling companies for the 12 secondary indexes and some of the latest quantitative data and remaining qualitative data. Qualitative data is determined by the power company staff and relevant experts. Due to the different dimensions of the data, it is necessary to standardize the processing and carry out the $[0,1]$ scale. Then, the classical domain, the node domain and the matter-element to be evaluated are normalized: 


\begin{tabular}{|c|c|c|c|c|c|c|}
\hline$P_{1}$ & $c_{1}$ & $(0.9,1)$ & $P_{2}$ & $c_{1}$ & $75,0.9)$ & \\
\hline & $c_{2}$ & $(0.8,1)$ & & $c_{2} \quad(0.7$, & $7,0.8)$ & \\
\hline & $c_{3}$ & $(0.75,1)$ & & $(0.6$ & $65,0.75)$ & \\
\hline & $c_{4}$ & $(0.9,1)$ & & $c_{4} \quad(0.8$, & $8,0.9)$ & \\
\hline & $c_{5}$ & $(0.8,1)$ & & $c_{5} \quad(0.7$, & $7,0.8)$ & \\
\hline & $c_{6}$ & $(0.8,1)$ & & $(0.7$ & $7,0.8)$ & \\
\hline & $c_{7}$ & $(0.85,1)$ & $R_{2}=$ & $c_{7} \quad(0.7$, & $7,0.85)$ & \\
\hline & $c_{8}$ & $(0.8,1)$ & & $(0.6$ & $65,0.8)$ & \\
\hline & $c_{9}$ & $(0.8,1)$ & & $(0.7$, & $7,0.8)$ & \\
\hline & $c_{10}$ & $(0.9,1)$ & & $(0.7$ & $75,0.9)$ & \\
\hline & $c_{11}$ & $(0.9,1)$ & & $C_{11} \quad(0.7$ & $75,0.9)$ & \\
\hline & $c_{12}$ & $(0.8,1)$ & & $c_{12} \quad(0.6$ & $65,0.8)$ & \\
\hline$P_{3}$ & $P_{3} \quad c_{1}$ & $(0.6,0.7$ & & $P_{4} \quad C_{1}$ & $(0.4,0$. & \\
\hline & $c_{2}$ & $(0.6,0.7$ & & $c_{2}$ & $(0.4,0$ & \\
\hline & $c_{3}$ & $(0.55,0$ & $.65)$ & $c_{3}$ & $(0.35,0$ & 55) \\
\hline & $c_{4}$ & $(0.6,0.8$ & & $c_{4}$ & $(0.45,0$ & \\
\hline & $C_{5}$ & $(0.6,0.7$ & & $c_{5}$ & $(0.4,0$ & \\
\hline & $c_{6}$ & $(0.6,0.7$ & & $c_{6}$ & $(0.45,0$ & \\
\hline & $c_{7}$ & $(0.55,0$ & $.7)$ & $c_{7}$ & $(0.35,0$ & 55) \\
\hline & $c_{8}$ & $(0.55,0$ & $.65)$ & $c_{8}$ & $(0.3,0$ & \\
\hline & $C_{9}$ & $(0.6,0.7$ & & $c_{9}$ & $(0.4,0$. & \\
\hline & $c_{10}$ & $(0.6,0$. & 75) & $c_{10}$ & $(0.4,0$ & \\
\hline & $c_{11}$ & $(0.6,0.7$ & 75) & $c_{11}$ & $(0.45$ & $.6)$ \\
\hline & $c_{12}$ & $(0.55,0$ & $0.65)\rfloor$ & $c_{12}$ & (0.35, & $.55)$ \\
\hline & $P_{5}$ & $C_{1}$ & $, 0.4)$ & & $P_{0} \quad C_{1}$ & 0.8 \\
\hline & & $c_{2} \quad(\mathrm{O}$ & $, 0.4)$ & & $C_{2}$ & 0.75 \\
\hline & & $C_{3} \quad(O$ & $, 0.35)$ & & $C_{3}$ & 0.76 \\
\hline & & $C_{4} \quad(\mathrm{O}$ & $, 0.45)$ & & $C_{4}$ & 0.83 \\
\hline & & $c_{5} \quad(\mathrm{O}$ & $, 0.4)$ & & $C_{5}$ & 0.68 \\
\hline$=$ & & $c_{6} \quad(\mathrm{O}$ & $, 0.45)$ & - & $c_{6}$ & 0.72 \\
\hline & & $c_{7} \quad(\mathrm{O}$ & $, 0.35)$ & 0 & $C_{7}$ & 0.6 \\
\hline & & $C_{8} \quad(\mathrm{O}$ & $, 0.3)$ & & $C_{8}$ & 0.5 \\
\hline & & $c_{9} \quad(\mathrm{O}$ & $, 0.4)$ & & $C_{9}$ & 0.75 \\
\hline & & $c_{10}$ & $0,0.4)$ & & $c_{10}$ & 0.88 \\
\hline & & $c_{11}$ & $0,0.45)$ & & $C_{11}$ & 0.7 \\
\hline & & $c_{12}$ & $0,0.35)$ & & $C_{12}$ & 0.75 \\
\hline
\end{tabular}


After determining the classical domain and the matter element to be evaluated, it is very possible to calculate the membership degree of the object to be evaluated according to the formula. It is shown as follows:

$$
\begin{gathered}
K_{1}\left(P_{0}\right)=\sum_{j=1}^{12} w_{j} K_{1}\left(v_{j}\right)=-0.213 \\
K_{2}\left(P_{0}\right)=\sum_{j=1}^{12} w_{j} K_{2}\left(v_{j}\right)=0.189 \\
K_{3}\left(P_{0}\right)=\sum_{j=1}^{12} w_{j} K_{3}\left(v_{j}\right)=-0.177 \\
K_{4}\left(P_{0}\right)=\sum_{j=1}^{12} w_{j} K_{4}\left(v_{j}\right)=-0.441 \\
K_{0}\left(P_{0}\right)=\sum_{j=1}^{12} w_{j} K_{0}\left(v_{j}\right)=-0.619
\end{gathered}
$$

From the above results, it can be seen that the operational risk evaluation level of the electricity selling company has the highest degree of the "risk high" evaluation grade, and is biased to the " general risk " level. Therefore, the operating risk evaluation level of the electricity selling company is "high risk"'.

\section{CoNCLUSION}

First, in this paper, the index system of operational risk evaluation for electricity selling companies is established, and 4 first grade indexes and 12 secondary indexes are determined. Then, the matter-element extension model which can fully consider the factors of material and quantity of things to be evaluated is taken as the evaluation model. Finally, an electric company is selected as an example to analyze its operational risk degree.

\section{ACKNOWLEDGMENT}

Supported by “the Fundamental Research Funds for the Central Universities”. Research on the Coordination Optimization Model and Simulation Platform among Power Generation, Grid, Load and Storage2015MS19.The corresponding author is Mi Liu.

\section{REFERENCES}

[1] Cai Chengkai. Research on investment risk management of power grid enterprises [D]. North China Electric Power University (Beijing),2011.

[2] Zhou Ming, Li Gengyin, Liu Min. Research on electricity procurement strategy for the utility in power markets. IEEAPSCOM ,2013,11-17.

[3] Vazquez C,Rivier M,Perez-Arriaga.If Pay-as-bid Auctions Are Not a Solution for California,then Why Not a Reliability Market.The Electricity Joumal,2001,14(4):41-48

[4] Celebi E, Fuller J D. A Model For Efficient Consumer Pricing Schemes In Electricity Markets[J]. Power Systems IEEE Transactions on, 2007, 22(1):60 - 67.

[5] Valery A. Kholodnyi. Modeling power forward prices for power with spikes: a non-Markovian approach [J], Nonlinear Analysis 63 (2005) 958 -965. 